\title{
Wendelstein 7-X - Commissioning of the Superconducting Magnet System
}

\author{
Konrad Risse, Dietrich Birus, Stephan Bosch, Victor Bykov, André Carls, Chandra P. Dhard, Joris Fellinger, \\ Thomas Mönnich, Michael Nagel, Matthias Otte, Thomas Rummel, Matthias Schneider
}

\begin{abstract}
The Wendelstein 7-X stellarator (W7-X), one of the largest stellarator fusion experiments, is presently being taken into operation at the Max Planck Institute for Plasma Physics in Greifswald. The main objective of the experiment is to prove the reactor relevance of the optimized stellarator concept. The $\mathrm{W7-X}$ experiment has a superconducting magnet system with 50 nonplanar and 20 planar coils grouped in five equal modules, electrically connected in seven circuits with 10 coils of each type. The connections between the coils are made by superconducting bus bars using the same NbTi Cable-in-Conduit Conductor as used for the superconducting coils. Specially developed high temperature superconducting current leads feed the current into the cryostat by bridging the temperature gradient from room temperature down to the $4 \mathrm{~K}$ level. Seven power supplies provide individual currents in the seven circuits. The quench detection system checks permanently the superconducting system regarding the occurrence of a quench. In case of a quench, the magnet safety system has to be activated and a set of switches lead the current into dump resistors. The commissioning of the magnet system was successfully performed until July 2015 with tests of the complete magnet system functionality needed for plasma operation, at a magnetic field of $2.5 \mathrm{~T}$.
\end{abstract}

Index Terms - Commissioning, Stellarator, Superconducting Magnets, Wendelstein 7-X

\section{INTRODUCTION}

$\mathrm{T}$ HE W7-X fusion experiment has a superconducting magnet system consisting of 50 non-planar and 20 planar coils. Seven electrical circuits with 10 coils each (connected in series) allow providing individual currents in the 7 coil types (see Fig. 1). The magnet system commissioning was successfully performed during the period between May and July 2015. The first plasma experiment campaign requires a magnetic field with $2.5 \mathrm{~T}$ on the plasma axis. The commissioning started with tests on the single coil type circuits and was continued with tests on the complete system. The magnet system and the W7-X support structure are equipped with a large set of temperature and mechanical sensors. The magnet commissioning was accompanied by an

This work has been carried out within the framework of the EUROfusion Consortium and has received funding from the Euratom research and training program 2014-2018 under grant agreement No 633053. The views and opinions expressed herein do not necessarily reflect those of the European Commission.

Konrad Risse, Dietrich Birus, Stephan Bosch, Victor Bykov, André Carls, Chandra P. Dhard, Joris Fellinger, Thomas Mönnich, Michael Nagel, Matthias Otte, Thomas Rummel, Matthias Schneider are with the Max-Planck-Institut für Plasmaphysik, Euratom Association, Wendelsteinstraße 1, Germany 17489 Greifswald (e-mail: konrad.risse@ipp.mpg.de). online monitoring and evaluation of the mechanical sensors to guarantee a proper function of the support structure. Subsequent to the magnet system commissioning, the magnetic flux surface measurements started with an extensive survey program checking the accuracy of the magnetic field [1],[2].

\section{Superconducting MAGnet System Components}

\section{A. Superconducting Coils}

The superconducting coils and their interconnecting bus bar system use the same Cable in Conduit Conductor (CICC). The conductor comprises of a cable with $243 \mathrm{NbTi}$ strands enveloped by an Aluminum (Al) jacket. Five different NonPlanar Coil (NPC) types with 10 coils each, provide the main magnetic stellarator field. The stellarator field can be modified by two different Planar Coil (PC) types with 10 coils each [3].

The NPC are made of 108 turns in 6 double layers and the PC have 36 turns in 3 double layers. The double layers are connected electrically in series and hydraulically in parallel. The electrical joints are specified with a resistance $<1 \mathrm{nOhm}$. The vacuum pressure impregnated winding packs are embedded into a heavy stainless steel casing.

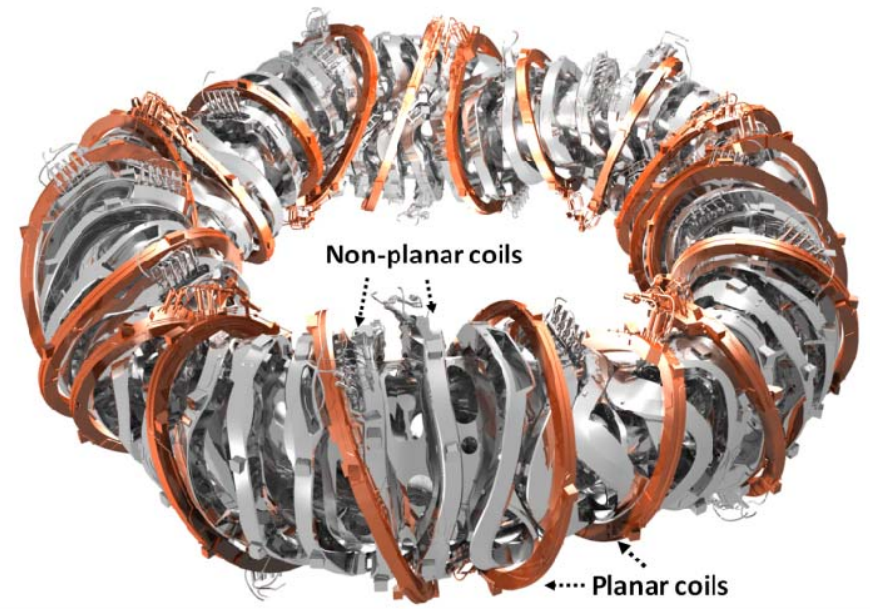

Fig. 1. Schematic view on the superconducting magnets system with 50 nonplanar coils and 10 planar coils.

The coils are equipped with an extensive set of sensors e.g. temperature measurements on the $\mathrm{He}$-inlets and outlets on the winding pack as well as on the casing cooling system, strain gauges on highly loaded positions on the support structure and distance sensors to measure distance changes between coils. 


\section{B. Current Leads and Superconducting Bus}

The 10 coils of the same coil type are connected in series by a superconducting bus section. In total 121 bus sections connect the coils in the seven circuits. The bus system uses the W7-X superconductor type with slightly rounded jacket edges to allow bending in all directions.

Specially developed high temperature superconducting Current Leads (CL) feed the current into the cryostat by bridging the temperature gradient from room temperature down to the $4 \mathrm{~K}$ level [4]. A copper cylinder takes over the current from the power supply at the warm side of the CL, leads the current through a high-temperature superconductor section and at the cold side through a copper bar with $\mathrm{Nb}_{3} \mathrm{Sn}$ rods to the connected bus bar. Fourteen CL operate in the seven coil circuits with the ability to carry steady state currents of $18.2 \mathrm{kA}$ and to withstand a voltage strength up to $13 \mathrm{kV}$ against ground potential in case of a fast discharge.

\section{Quench Detection System}

The Quench Detection System (QDS) monitors the superconducting components continuously regarding the development of voltages which indicates the loss of superconductivity [5]. By comparison of two section voltages (one double layer is one section) in one quench detection unit, the QDS is able to eliminate electromagnetic interferences and to detect voltage differences between the two sections. The magnet safety system is triggered on two independent redundant interfaces in case of a quench.

\section{Power Supplies with Coil Protection System}

Each of the seven coil circuits has its own power supply to provide individual currents. The construction of the power supplies with the integrated magnet safety system is similar for all circuits. Two transformers connected to the $20 \mathrm{kV}$ grid in connection with a 12 pulse converter create a DC voltage up to $30 \mathrm{~V}$. The magnet safety system is activated in case of a quench and the coil energy is dumped into nickel resistors with a non-linear resistance characteristic [6].

\section{COMMISSIONING OF THE MAGNET SYSTEM}

\section{A. Commissioning Strategy}

The first operation phase of W7-X requires a magnetic field of $2.5 \mathrm{~T}$ on the plasma axis. To provide the magnetic field in the first operational phase the five NPC circuits will be operated with $12.8 \mathrm{kA}$ and the two PC circuits with $5 \mathrm{kA}$ respectively.

The commissioning strategy has to respond to the following challenges: the power supplies operate first time with full inductive load of $1 \mathrm{H}$ for non-planar coil circuits and $0.4 \mathrm{H}$ for planar coil circuits respectively, the superconducting bus bars with the related joint connections carry for the first time an electrical current and the QDS needs a balancing process for the internal measurement bridge with current ramps while the QDS is not functional.

The objective of the commissioning phase was:

- Stepwise commissioning of the magnet system components with full functionality for steady state operation by observing at least $1 \mathrm{~K}$ safety margin for superconducting components.

- Adjustment of cooling flow in the superconducting parts especially the current leads.

- Continuous monitoring of the mechanical sensors, of the He flow and the component temperatures. Benchmarking of the data with the Finite Element (FE) models or with specified values.

TABLE I

MAGNET SYSTEM COMMISSIONING PHASES

\begin{tabular}{|c|c|c|c|}
\hline Commissioning Phase & $\begin{array}{l}\text { NPC } \\
\text { Current }\end{array}$ & $\begin{array}{l}\text { PC } \\
\text { Current }\end{array}$ & Condition \\
\hline $\begin{array}{l}\text { 1st phase } \\
\text { single coil circuit } \\
\text { operation }\end{array}$ & $500 \mathrm{~A}$ & $500 \mathrm{~A}$ & $\begin{array}{l}\text { balance of quench } \\
\text { detection units, } \\
\text { without active } \\
\text { QDS }\end{array}$ \\
\hline $\begin{array}{l}\text { 2nd phase } \\
\text { single coil circuit } \\
\text { operation }\end{array}$ & $\begin{array}{l}2 \mathrm{kA} \\
6 \mathrm{kA} \\
10 \mathrm{kA} \\
\left(^{*}\right) 12.8 \mathrm{kA} \\
- \\
-\end{array}$ & $\begin{array}{l}- \\
- \\
- \\
- \\
2 \mathrm{kA} \\
5 \mathrm{kA}\end{array}$ & $\begin{array}{l}\text { single circuit tests } \\
\text { with activation of } \\
\text { magnet safety } \\
\text { system } \\
(*) \text { only NPC type } \\
2,3,4\end{array}$ \\
\hline $\begin{array}{l}3^{\text {rd }} \text { phase } \\
\text { Integrated coil circuit } \\
\text { operation }\end{array}$ & $\begin{array}{l}2 \mathrm{kA} \\
6 \mathrm{kA} \\
10 \mathrm{kA} \\
12.8 \mathrm{kA}\end{array}$ & $\begin{array}{l}0.78 \mathrm{kA} \\
2.34 \mathrm{kA} \\
3.90 \mathrm{kA} \\
5.0 \mathrm{kA}\end{array}$ & $\begin{array}{l}\text { Integrated tests } \\
\text { with all seven } \\
\text { circuits in parallel }\end{array}$ \\
\hline
\end{tabular}

The commissioning was structured into 3 main phases, see Table I. The $1^{\text {st }}$ phase was necessary to bring the QDS into operation by a balancing program with $500 \mathrm{~A}$ pulses in each single coil circuit. During this phase the QDS was not active. Analysis had shown that the superconducting parts e.g. coils or the bus system could carry the relative low current of $500 \mathrm{~A}$ even in normal conductive state.

TABLE II

$2^{\mathrm{ND}}$ COMMISSIONING PHASE - SINGLE COIL CIRCUIT TEST PROGRAM FOR NPC

\begin{tabular}{llll}
\hline \hline Current levels & Ramp up & Plateau Phase & Ramp Down \\
\hline $2 \mathrm{kA}$ & $30 \mathrm{~A} / \mathrm{s}$ & $1 \mathrm{~h}$ & $30 \mathrm{~A} / \mathrm{s}$ \\
$6 \mathrm{kA}$ & $30 \mathrm{~A} / \mathrm{s}$ & $10 \mathrm{~min}$ & Inverter discharge \\
$10 \mathrm{kA}$ & $30 \mathrm{~A} / \mathrm{s}$ & $10 \mathrm{~min}$ & Fast discharge \\
& $30 \mathrm{~A} / \mathrm{s}$ & $10 \mathrm{~min}$ & $30 \mathrm{~A} / \mathrm{s}$ \\
\hline $12.8 \mathrm{kA}\left(^{*}\right)$ & $30 \mathrm{~A} / \mathrm{s}$ & $1 \mathrm{~h}$ & $30 \mathrm{~A} / \mathrm{s}$ \\
& $30 \mathrm{~A} / \mathrm{s}$ & $4 \mathrm{~h}$ & Inverter discharge \\
$\left(^{*}\right)$ only NPC & $30 \mathrm{~A} / \mathrm{s}$ & $10 \mathrm{~min}$ & Fast discharge \\
type 2, 3, 4 & $30 \mathrm{~A} / \mathrm{s}$ & $10 \mathrm{~min}$ & $30 \mathrm{~A} / \mathrm{s}$ \\
\hline \hline
\end{tabular}

The functionality of the single coil circuit components was tested in the $2^{\text {nd }}$ commissioning phase while the current levels were stepwise increased. To avoid overloading and excessive displacements for NPC 1 and 5 - the current was limited to $10 \mathrm{kA}$ for these types. The test steps for the NPC are described in Table II.

The different discharge procedures, including a fast discharge by activation of the magnet safety system, were tested at each current level. A $4 \mathrm{~h}$ plateau phase was introduced at the highest current level to adjust the cooling flow in the current leads. The temperature of the superconducting coils, the bus bar sections and the current leads were carefully monitored during the tests. Each current 
change of $1000 \mathrm{~A}$ or even higher is accompanied by a so called in service high voltage test to check the insulation integrity. The measurement data coming from the strain gauges, distance sensors and contact sensors were analysed during the whole test program to check the mechanical integrity of the support structure.

In the $3^{\text {rd }}$ commissioning phase the test sequence from Table II was repeated with all seven coil circuits in parallel operation - current values shown in Table I. Finally the current in the PC was varied between $0 \mathrm{kA}$ and $5 \mathrm{kA}$ while the NPC carried $12.8 \mathrm{kA}$.

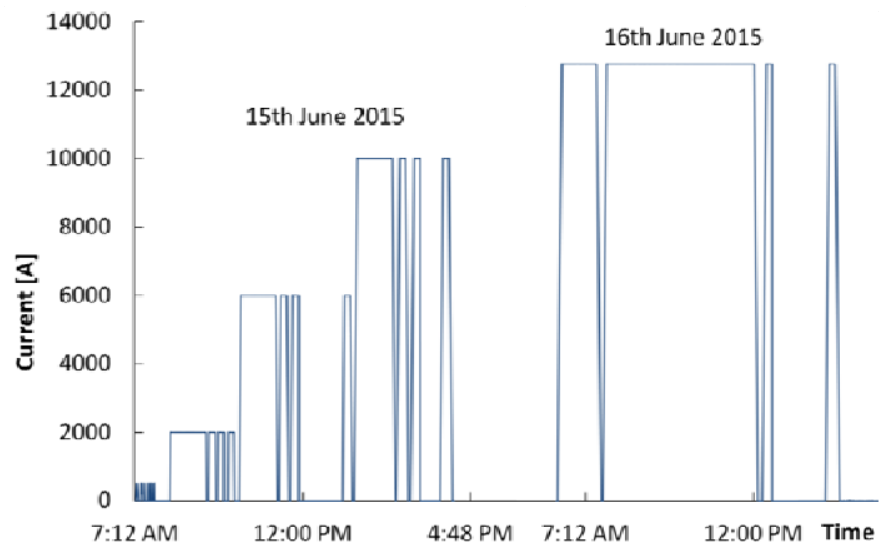

Fig. 2. Single coil circuit current tests on non-planar coil type 4 (NPC4).

\section{B. Magnet System Commissioning Results}

Fig. 2 shows the $1^{\text {st }}$ and $2^{\text {nd }}$ commissioning phases on the single circuit of NPC type 4 performed during two days, (according to Table I and II). The $500 \mathrm{~A}$ pulses for balancing the QDS became necessary after the very first switch on experiences. The quench signal forwarding to the magnet safety system was interrupted during this QDS balancing phase. After that phase the QDS was fully functional in operation. The $2^{\text {nd }}$ phase contains 4 current levels with a similar test procedure. The magnet safety system was tested at each current level during fast discharges with increased energy dissipation into the dump resistor.

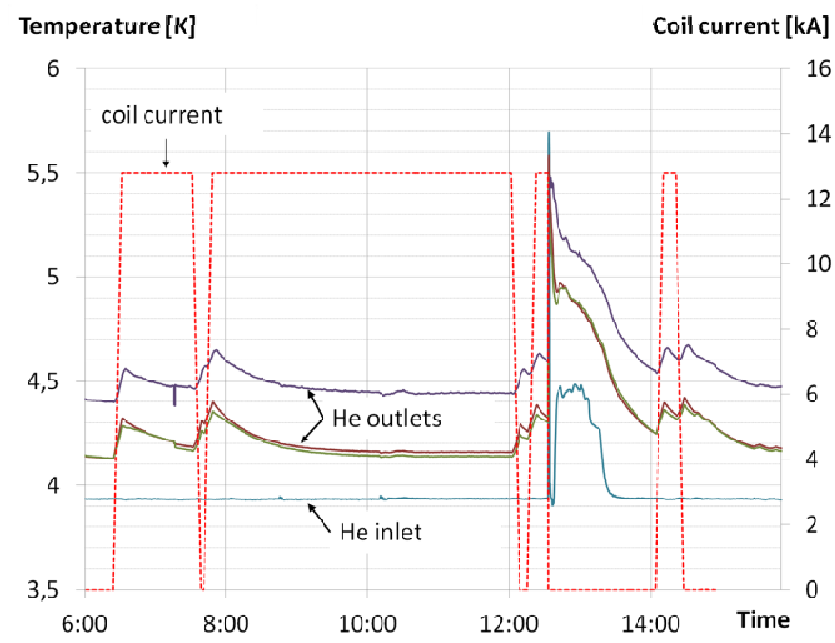

Fig. 3. Temperature behavior during current tests of non-planar coil type 4 on $16^{\text {th }}$ June 2015, the temperatures are the mean values of the 10 series connected coils.
Fig. 3 presents the temperature behaviour of the NPC4 coil types during current ramps and during plateau phases. AC losses during the current ramps of $30 \mathrm{~A} / \mathrm{s}$ increase the temperature on the winding outlet of about $0.2 \mathrm{~K}$. A fast discharge with ramps of $5000 \mathrm{~A} / \mathrm{s}$ increases the outlet temperature of about $1.3 \mathrm{~K}$ while the casing temperature increases up to $10 \mathrm{~K}$. The ohmic heating losses in the coils can be derived from the temperature differences between inlet and outlet by comparison of phases with and without current. As result of this comparison, the ohmic heating leads to a $38 \mathrm{mK}$ temperature increase in average implying $2.9 \mathrm{nOhm}$ resistance in the coil during plateau phase. This value is determined by the five internal normal conductive joints connecting the six double layers in series. The $2.9 \mathrm{nOhm}$ value is well below the specified joint resistance.

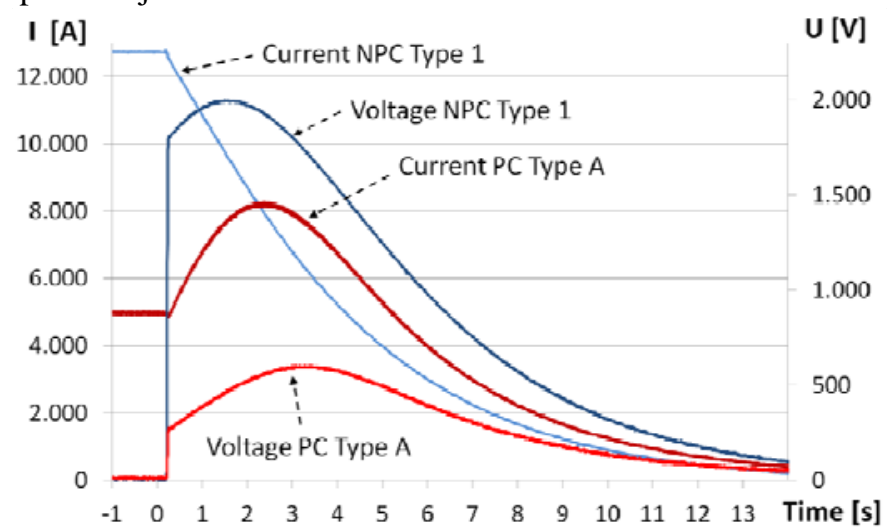

Fig. 4. Current and voltage of non-planar coil type 1 and planar coil type A during a fast discharge.

The voltages and the current data were recorded during the fast discharge tests in all seven circuits in the $3^{\text {rd }}$ commissioning phase. As an example Fig. 4 presents data recorded on the NPC type 1 and PC type A. While the NPC were operated at $12.8 \mathrm{kA}$ and the planar coils with $5 \mathrm{kA}$ respectively, a fast discharge was initiated to check the magnet safety function. The magnet system stores $430 \mathrm{MJ}$ at this stage, during a fast discharge the energy is conducted into dump resistors for commutation into heat. As predicted in the models the current in the planar coils increases by about $60 \%$ during the first seconds of the fast discharge due to the inductive coupling between all coils.

\section{ANALYSIS OF RESULTS}

\section{A. Mechanical Sensor Data Evaluation}

The superconducting magnet system is equipped with a large set of mechanical sensors to guarantee a proper function of the W7-X machine and to verify numerical models [7]. The areas of most attention on the magnets are; displacements between coils or between coils and neighboring components, mechanical loads on the coil support elements and collisions of components in the cryostat. About 510 strain gauges measure the strain on magnet system components, 58 distance sensors monitor coil displacements and 88 contact sensors check collisions between the coils and the cryostat system.

Fig. 5 compares the FE model prediction with measured 
values exemplarily for the displacements between NPC1 and NPC2 in the 2.5 T configuration. The measured displacements can rise up to $2.2 \mathrm{~mm}$. The prediction is generally above the measured values, because the FE model contains a safety margin. The present quality of the FE-predictions is within a range of $20 \%$ for the displacements.

The vertical displacements of the PC can be qualitatively predicted, but not at the same accuracy as for the NPC, because their support-system is complex and relies mainly on contacts.

\section{Distance sensors dl [mm]}

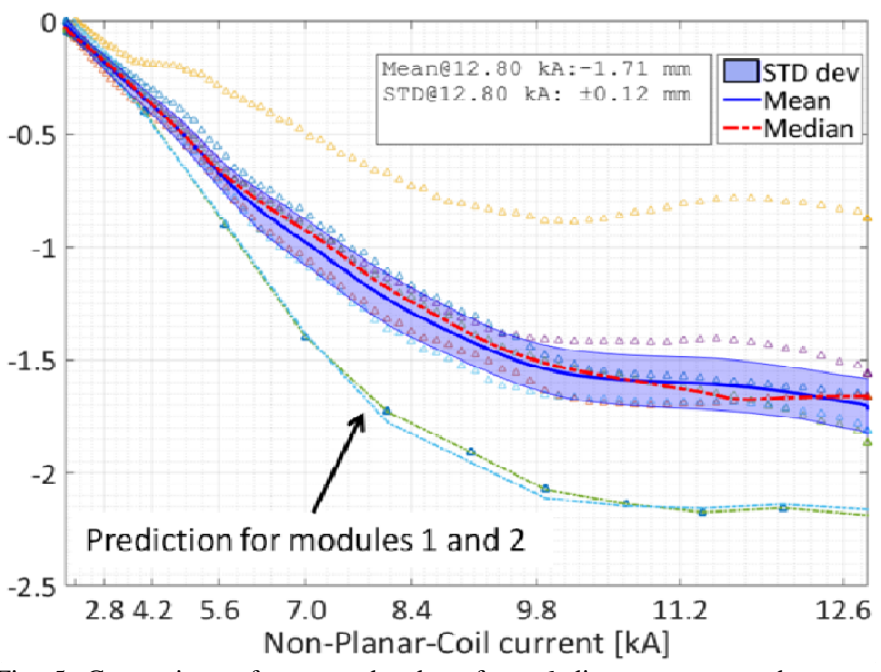

Fig. 5. Comparison of measured values from 6 distances sensors between NPC 1 and NPC 2 (triangles) with the predicted displacements in all five modules of W7-X during the $2.5 \mathrm{~T}$ configuration, mean value considers 5 out of 6 sensors.

TABLE III

ACCURACY OF FE-MODEL AND MEASURED VALUES FOR SELECTED SENSORS FOR 2.5 T LIMITER CONFIGURATION

\begin{tabular}{lcc}
\hline \hline Sensors & $\begin{array}{c}\text { Mean absolute } \\
\text { Difference }\end{array}$ & Standard Deviation \\
\hline NPC strain gauges & $-10 \mathrm{MPa}$ & $\pm 20.5 \mathrm{MPa}$ \\
\hline PC strain gauges & $4.35 \mathrm{MPa}$ & $\pm 2.9 \mathrm{MPa}$ \\
\hline $\begin{array}{l}\text { Distance NPC to NPC } \\
32 \text { out of } 58 \text { sensors }\end{array}$ & $0.084 \mathrm{~mm}$ & $\pm 0.58 \mathrm{~mm}$ \\
\hline \hline
\end{tabular}

As a conclusion, no problems were observed during close monitoring of the magnet system behavior. Nevertheless, the quality of the FE-models of the magnet system could be improved in few locations, based on consistent strain/ displacement measurements, to obtain a better agreement in future.

\section{B. Magnetic Flux Surface Measurements -First Results}

The flux surface diagnostic enables measuring directly the structure of the magnetic field [1]. For this purpose, an electron beam with a beam intensity of about $1 \mathrm{~mA}$ and an accelerating energy of a few ten $\mathrm{eV}$ is injected, which moves along a field line under observation in the evacuated plasma vessel. The trajectory of the beam can be visualized due to inelastic collisions with a background gas e.g. nitrogen or hydrogen resulting in a light emission. A tangentially orientated camera made the observation of the tracer. Fig. 6 presents a photo of a single flux surface obtained during a sweep with the fluorescent detector rod through the plasma vessel cross section. Light spots are created when the electron beam hits the rod, which can be observed by the camera.

The initial magnetic flux surface measurements confirm so far the existence of good and nested magnetic flux surface up to the nominal field strength of $2.5 \mathrm{~T}$ without significant errors. The measured position and shape of the magnetic flux surfaces are in good agreement with simulations and validate the magnetic field models.

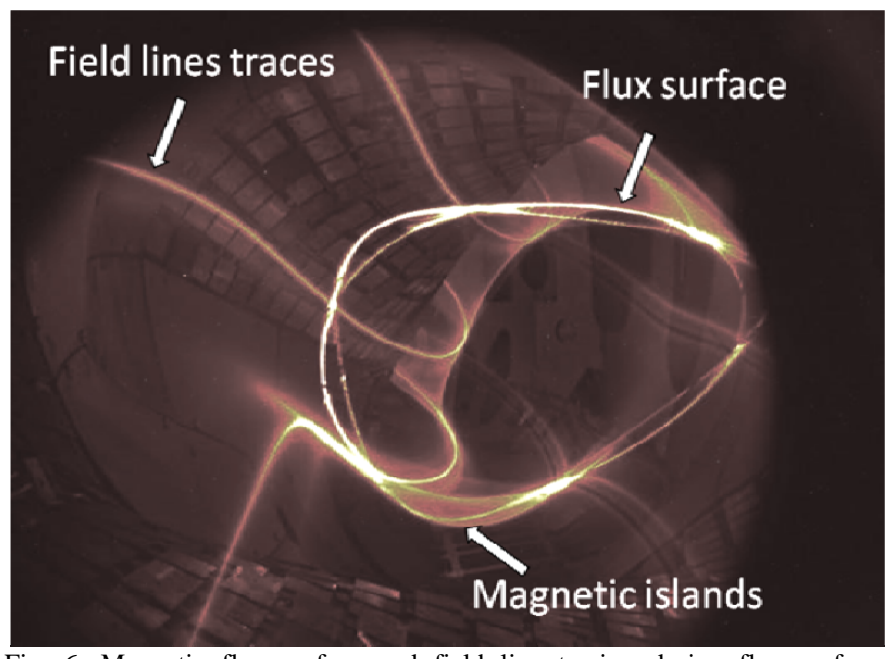

Fig. 6. Magnetic flux surface and field line tracing during flux surface measurements.

\section{CONCLUSIONS}

The W7-X superconducting magnet system commissioning for $2.5 \mathrm{~T}$ operation on plasma axis was successfully accomplished until July 2015. Extensive tests were performed which confirm the full functionality for the first operational phase of W7-X. The magnetic flux surface diagnostic verified the magnetic flux surfaces with the models. This is an impressive confirmation of the accurate manufacturing and assembly of the W7-X superconducting magnet system.

\section{ACKNOWLEDGMENT}

Sincere thanks to all my colleagues from the W7-X operations division, the magnet system group members and the complete W7-X team for their support.

\section{REFERENCES}

[1] H. S. Bosch et al., "Transition from Construction to Operation Phase of the Wendelstein 7-X Stellarator", IEEE Transactions on Plasma Science, Vol. 42, 432 (2014).

[2] H. S. Bosch et al., "Experience from Construction to Operation Phase of the Wendelstein 7-X Stellarator", Fusion Engineering and Design, 9697 (2015), pp. 22-27.

[3] K. Riße, "Fabrication of the superconducting Coils for Wendelstein 7X”, Fusion Engineering and Design , 66-68 (2003), pp 965-969.

[4] T.Rummel, "Current Leads for the Wendelstein 7-X superconducting Magnet System”, IEEE Transactions on Plasma Science, Vol.42, No.8, 2014, pp. $2146-2153$.

[5] D. Birus, "The Quench Detection system of Wendelstein 7-X”, Fusion Engineering and Design, 86 (2011), pp. 1566-1570.

[6] T. Rummel, "Power Supplies for the Wendelstein 7-X stellarator", Fusion Engineering and Design, 66-68 (2003), pp. 1115-1118.

[7] V. Bykov et al., "W7-X Mechanical Instrumentation System for Commissioning and Operation”, Fusion Science and Technology, v.68 no. 2 (2015). 
4OrCB-03 